\title{
THE LAW OF POLICE ENTRAPMENT: CRITICAL EVALUATION AND POLICY ANALYSIS
}

\begin{abstract}
This article provides a critical analysis of the law of police entrapment and proposes a new foundation for this law. The article shows that the 'shift of scene' assumption underlies existing and proposed legal tests for the legitimacy of entrapment. According to this assumption, in some identifiable cases the defendant would have committed a similar offence at a different time and location absent police entrapment. In these cases, entrapment is morally and economically insignificant and hence legitimate. Using probabilistic analysis, the article advances the argument that the 'shift of scene' assumption is misguided. Entrapment actually changes (usually raises) the probability of commission, and hence also the defendant's punishment expectancy, in almost all cases. This increase is hard to justify on grounds of justice or on economic grounds. The article then proposes a different basis for the analysis of entrapment, building on the idea of reallocation of burdens: where the defendant creates particularly heavy burdens that go beyond the offence's harm expectancy, it is justified to increase his punishment expectancy through entrapment. Furthermore, entrapment should be conceptualized as a mitigating factor, thus allowing the courts to 'correct' exaggerated or undue increases in the defendant's punishment expectancy.
\end{abstract}

\section{INTRODUCTION}

Drug dealing around schools is a pressing issue. The police send a young and boyish-looking police officer to hang around a school and ask passers-by if they could get him some Heroin for a good price. Now consider two scenarios: in the first, the school is in a neighbourhood with high crime rates, and John, a drug dealer, is entrapped. In the second, the school is in a middle-class neighbourhood free of crime, and Donna is entrapped. Donna has never sold drugs before but is now in great financial difficulties; as the undercover

* Liat Levanon is with Brunel Law School, Brunel University London. I thank Dimitrios Giannoulopoulos and Paul Roberts for their important comments on previous drafts. E-mail: liat.levanon@brunel.ac.uk; liatlevanon@gmail.com 
approaches her, she remembers a childhood friend whom she has not seen for years but knows might be able to provide her with Heroin.

'Gut feeling' tells us that Donna's entrapment is illegitimate. ${ }^{1}$ What about John? Probably, many would feel that his entrapment does not give rise to special difficulties. In law, the European, the English, the Canadian, and the American tests for entrapment would lead to the same conclusions. The European Court of Human Rights has acknowledged the legitimacy of police action in cases like John's, where there was no such an influence on the defendant as to incite the commission of an offence that would otherwise not have been committed. ${ }^{2}$ On the other hand, in Donna's case the offence would not have been committed if it were not for police intervention, and hence the entrapment is illegitimate. According to the English test, John's entrapment is legitimate since the police did nothing more than providing him with an unexceptional opportunity to sell Heroin. ${ }^{3}$ Donna, on the other hand, was provided with an exceptional opportunity to commit crime, and thus her entrapment is illegitimate. Similarly, according to the Canadian test, John's entrapment is legitimate since the police undertook a bona fide investigation directed at an area where it is reasonably suspected that criminal activity is occurring, and they did not go beyond providing John with an opportunity to sell Heroin. ${ }^{4}$ Donna's entrapment is illegitimate since police action was not part of such a bona fide investigation, and in addition, their offer of a reward which was unusual in the circumstances seems to have induced Donna to sell Heroin. And according to the prevailing subjective version of the American test, police inducement was offered to John who was already predisposed to commit the offence, and hence his entrapment is legitimate. Donna, on the other hand, was provided

${ }^{1}$ I am drawing here on Gerald Dworkin's approach to the analysis of entrapment in Gerald Dworkin, 'Ethics and Entrapment', Journal of Social Issues 43 (1987) p. 57. See also Gerald Dworkin, 'The Serpent Beguiled Me and I Did Eat: Entrapment and the Creation of Crime', (1985) 4 Law and Philosophy 17.

${ }^{2}$ Ramanauskas v. Lithuania App no 74420/01, IHRL 3267 (ECHR 2008), 5th February 2008, [GC], § 55. The determination is done with reference to various factors such as the existence of objective suspicion that the defendant had been involved in criminal activity or was predisposed to commit a similar offence. Bannikova v. Russia, unreported, App no 18757/06, 4 November 2010 (ECtHR) § 38.

${ }^{3}$ R v Looseley; Attorney-General's Reference (No. 3 of 2000), [2001] 1 WLR 2060. For criticism see Dan Squires, 'The Problem with Entrapment', (2006) 26 Oxford Journal of Legal Studies 351.

${ }^{4}$ R.v.Mack 1988 CanL1l 24 (S.C.C.) (1988) 44 C.C.C. (3d) 513 (S.C.C.) at p.559; R v Barnes, [1991] 1 SCR 449. 
with inducement despite not being predisposed to commit crime, and hence her entrapment is illegitimate. ${ }^{5}$ In a concurring judgement, Judge Richard Posner has suggested that American law should focus less on the defendant's psychology and more on police action, examining whether, considering the nature of this action, the defendant was likely to have committed similar crime at a different time and location absent the action (hereinafter: the 'shift of scene' assumption). ${ }^{6}$ This modified test would probably lead to similar conclusions: the police offered a good price for drugs, but it was still likely that John would commit similar crime even absent this offer; Donna, on the other hand, was unlikely to have resolved her financial difficulties in this way absent the offer.

The literature on entrapment revolves mainly around the existing legal tests. ${ }^{7}$ Some of it refines the tests or discusses their appropriate scope ${ }^{8}$ and much of it debates the 'subjectivism' of the prevailing American test and the 'objectivism' of many of the other tests, addressing the different values they promote and their different practical implications. ${ }^{9}$ Several authors have also recognized links

\footnotetext{
${ }^{5}$ See Sorrells v US 287 US 435. 452 (1932) and its subsequent interpretation in US v Russell 411 US 423, 429 (1973). For criticism see e.g. Kevin A. Smith, 'Psychology, Factfinding, and Entrapment', (2004) 103 Michigan Law Review 759; B. Grant Stitt and Gene G. James, 'Entrapment and the Entrapment Defence: Dilemmas for a Democratic Society', (1984) 3 Law and Philosophy 111 at 115-117. See also T. Ward Frampton, 'Predisposition and Positivism: The Forgotten Foundations of the Entrapment Doctrine' (2013) 103 J. Crim. L. \& Criminology 111. But compare with MPC $\S 2.13$.

${ }^{6}$ United States v. Kaminski, 703 F.2d 1004, 1010 (7th Cir. 1983). Posner's approach is discussed in Part I, Section A.

${ }^{7}$ See e.g. David M. Tanovich, 'Rethinking the Bona Fides of Entrapment' (2011) 43 U.B.C. L. Rev. 417; Andrew Choo, 'A Defence of Entrapment', (1990) 53 The Modern Law Review 453; Andrew Ashworth, 'What is Wrong with Entrapment', (1999) Sing. J. Legal Stud. 293; Andrew Ashworth, 'Re-Drawing the Boundaries of Entrapment' [2002] Crim LR 161; Andrew Ashworth, 'Testing Fidelity to Legal Values: Official Involvement and Criminal Justice', in S Shute and A Simester (eds), Criminal Law Theory: Doctrines of the General Part (Oxford: Oxford University Press, 2002) 315; Mike Redmayne, 'Exploring Entrapment' in L Zedner and J V Roberts (eds), Principles and Values in Criminal Law and Criminal Justice: Essays in Honour of Andrew Ashworth (Oxford: Oxford University Press, 2012) 157; HL Ho, 'State Entrapment' (2010) 31 Legal Studies 71; Smith, no. 5 above. For economic analysis of entrapment see J. Gregory Deis, 'Economics, Causation, and the Entrapment Defence' (2001) University of Illinois Law Review 1207.

${ }^{8}$ Redmayne, ibid., provides such a sophisticated analysis.

${ }^{9}$ Ashworth, 'What is Wrong with Entrapment', no. 7 above, and Choo, no. 7 above, are two examples of such discussions.
} 
between the tests. ${ }^{10}$ Nevertheless, the connection between the tests has not yet been explored in depth. There is no available analysis which identifies and criticizes the basic idea underlying both of them. This article aims to fill up that gap.

Setting margins aside, the tests have in common one basic idea ${ }^{11}$ : that the legitimacy of entrapment depends on the deviation it creates from the otherwise-expected course of events. Where the actual course of events (the 'entrapment course') is normatively similar to the otherwise-expected course of events, entrapment is legitimate. Where the actual course of events deviates from the otherwise-expected course of events, entrapment is illegitimate. The tests present different ways of comparing the actual course of events and a hypothetical course of events lacking police interference - either by focusing on the exceptionality of the opportunity the police presented compared to otherwise available opportunities, or by focusing on D's otherwise-expected course of conduct. Despite the different focus, both tests examine whether, looking at the entire picture (including police action and D's part), D would have committed a similar offence in the hypothetical course of events lacking police intervention.

By comparing the actual course of events with the hypothetical course of events the tests aim to identify the cases in which entrapment gives rise to no special difficulties and can be easily justified. If entrapment does not create normatively significant deviations from the expected course of events, it has no bearings for D's punishment expectancy prior to commission (it remains the same as it would have been absent the entrapment). Entrapment can then be justified on grounds of justice, as it gives $\mathrm{D}$ that which she deserves and nothing more - it does not make her worse off than she would have been absent police intervention. And it can also be justified on economic grounds, as it merely replaces the offence's harm expectancy with its correlating punishment expectancy the way criminal law is supposed to do to optimally deter from crime commission. ${ }^{12}$ Thus, where the tests apply, entrapment is legitimate.

\footnotetext{
${ }^{10}$ See Judge Posner's version of the American test; Ashworth, no. 7 above; Dworkin, no. 1 above; Squires, no. 3 above; L.M. Seidman 'The Supreme Court, Entrapment, and Our Criminal Justice Dilemma', (1982) Sup. Ct. Rev. 1981111.

${ }^{11}$ And indeed Ashworth notes that each of them could be modified in light of the other's policies and guiding principles. Ashworth, no. 7 above, 297.

${ }^{12}$ In an economic model of criminal law, the punishment expectancy for any offence is already calculated to be optimal (thus as long as it is not altered, optimal deterrence is achieved). For an economic model of criminal law see Gary S. Becker,
} 
The assumptions underlying this comparative approach are (1) that there are indeed cases where police intervention does not change D's punishment expectancy and hence does not create normatively significant deviations from the expected course of events, and (2) that the tests appropriately identify these cases. In other words, all the tests make good sense only under the 'shift of scene' assumption mentioned by Judge Posner. Where entrapment merely shifts the scene of crime, it does not change D's punishment expectancy, and hence it is justifiable. ${ }^{13}$

But the 'shift of scene' assumption is far from obvious. ${ }^{14}$ Probabilistic examination demonstrates that the 'shift of scene' assumption has no mathematical validity: police intervention hardly ever merely changes the timing and location of crime. Rather, police intervention increases the likelihood of crime commission in most cases. Furthermore, to the extent that there may be rare cases in which police intervention merely shifts the scene of crime, the existing tests cannot identify them. Accordingly, there is hardly any solid basis for the existing legal tests of entrapment.

Part I of the article advances this argument. After introducing two of the most powerful rationales proposed thus far for the law of entrapment, it uses simple probabilistic analysis and Bayesian methods to show that whether they encourage crime or merely provide an unexceptional opportunity to commit crime, whether $\mathrm{D}$ is already predisposed towards crime or engaged in crime or not, police action never merely shifts the scene of crime; it always changes the probability of crime commission. This change requires justification

Footnote 12 continued

'Crime and Punishment: An Economic Approach', in Gary S. Becker and William M. Landes eds. Essays in the Economics of Crime and Punishment (National Bureau of Economic Research: 1974) 1. The suggestion that for some offences the punishment expectancy is sub-optimal, and in such cases entrapment is legitimate, is discussed further in Part II, Section E.

${ }^{13}$ Part I, sections B and C(I) discuss two exceptional attempts to justify a presumed increase in punishment expectancy or part of it. See Thomas J. Miceli, 'Criminal Solicitation, Entrapment, and the Enforcement of Law', (2007) 27 International Review of Law and Economics 258; and another by Gerald Dworkin, 'The Serpent Beguiled Me and I Did Eat: Entrapment and the Creation of Crime', no. 1 above.

${ }^{14}$ Compare with Redmayne, no. 7 above, 167. Accordingly, Redmayne preferred a relatively narrow test allowing entrapment only of defendants who were already engaged in offending. Arguably, this test too relies on a 'shift of scene' assumption, even if it restricts the range of cases in which it claims to identify it. 
which the existing tests for entrapment and the rationales proposed for these tests fail to account for. Accordingly, the existing tests for entrapment lack a solid theoretical foundation.

If this is the case, a different rationale for a law of entrapment should be proposed, which might lead to different legal distinctions and to a different approach to entrapment. Part II of the article argues that what existing law and much literature fail to consider is the defensive nature of entrapment and accordingly its proximity to the doctrine of self-defence. It is submitted that the aim of both selfdefence and entrapment is to reallocate the risks and burdens D imposes on others. Accordingly, in appropriate cases, where these risks and burdens are sufficiently high, $\mathrm{D}$ exposes himself to a radical defensive response - be it by way of e.g. lethal self-defensive force or by way of entrapment. In other cases self-defensive force and entrapment are out of the question.

\section{PART I: PROBABILISTIC IMPLICATIONS OF POLICE ENTRAPMENT}

The basic assumption underlying the law of entrapment and its proposed rationales is that in some cases, entrapment merely shifts the scene of crime. Yet existing accounts of entrapment give rise to various difficulties, many of which are have to do with the falsehood of this underlying assumption: probabilistic analysis demonstrates that crime is never merely relocated.

\subsection{Standard Economic Accounts}

Standard economic analysis suggests that entrapment is cost-effective and legitimate where crime is relocated rather than created. In Judge Richard Posner's words in the American case of Kaminski, if the police are just inducing someone to commit sooner a crime he would have committed eventually, but do so in controlled circumstances where the costs to the criminal justice system of apprehension and conviction are minimized, the police are economizing on resources... If this is right, the implementing concept of 'predisposition to crime' calls less for psychological conjecture than for a common-sense assessment of whether it is likely that the defendant would have committed the crime anyway - without the blandishments the police used on him - but at a time and place where it would have been more difficult for them to apprehend him and the state to convict him, or 
whether the police used threats or promises so powerful that a lawabiding individual was induced to commit a crime. If the latter is the case, the police tactics do not merely affect the timing and location of a crime; they cause crime'. ${ }^{15}$ Thus, the central question concerns the likelihood that $\mathrm{D}$ would have committed the offence absent police intervention, ${ }^{16}$ and this question should be answered either in the positive or in the negative using 'common-sense assessment' and considering the nature of the inducement the police presented.

Posner's analysis compares the actual course of events with the otherwise-expected course of events. It builds on the 'likely-unlikely' binary, in which 'likely' is treated for purposes of the legal analysis as 'would have committed', and 'unlikely' is treated as 'would not have committed'. ${ }^{17}$ The rest of the analysis flows from this presumed binary: for those defendants who fall within the 'would have committed' category, police action does nothing much: these defendants 'would have committed' with or without police action; and thus police action merely affects the timing and location of crime, or shifts the scene of crime. On the other hand, for those defendants who fall within the 'would not have committed' category, police action changes category: they 'would not have committed' absent police action, but 'would have committed' with police action; and thus police action causes crime.

But in the sphere of likelihood and probability there is no 'likely' and 'unlikely' binary, and accordingly the police hardly ever merely shift the scene of crime or indeed cause crime in Posner's sense. Likelihood is continuous and accordingly 'likely' and 'unlikely' do not mean 'would have committed' and 'would not have committed'. There is, indeed, a binary of 'more likely than not to have committed' and 'less likely to have committed than not to have committed'. But this binary has no bearings for Posner's derivative distinction be-

${ }^{15}$ United States v. Kaminski, 703 F.2d 1004, 1010 (7th Cir. 1983) (Posner, J., concurring).

${ }^{16}$ Interestingly, Ho proposes a very similar test based on different considerations. For Ho, the relevant question is whether 'the crime with which the accused is charged is of a type that, without the state interference, he or she would probably never have committed' (no. 7 above, 95). Much of the criticism over Posner's test is relevant for Ho's test too.

${ }^{17}$ See also Deis, no. 7 above, 1230. Deis speaks of the probability that D is a true offender, assuming that he is either a 'true offender' or not, and that only our knowledge of the answer can be described in probabilistic terms. Speaking again in non-probabilistic terms, he further suggests on p. 1232 that society has no interest in entrapping people who are willing to commit crime for a price higher than current market price because they do not pose a threat. 
tween merely shifting the scene of crime and causing crime. The fact that D1 was less likely to have committed similar crime than not to have committed similar crime absent police intervention does not mean that the police created his crime - police intervention might not have changed the probability of commission, or it might even have decreased the probability of commission. And the fact that D2 was more likely than not to have committed similar crime absent police intervention does not mean that police intervention merely shifted the scene of the crime - police intervention might well have further increased this probability. Thus, the 'causing' - 'shifting the scene' distinction has no sound probabilistic basis to rely on.

To make this more apparent, let us assume that 'likely' reflects any probability that is above $50 \%$, and 'unlikely' reflects any probability that is below $50 \%$. Let us further ignore for the moment, as does Posner, the (relevant) question of the cost of enforcement. ${ }^{18}$ It is hard to see why entrapping D1 whose likelihood of commission is $40 \%$ causes crime and is a mere waste of resources, while entrapping D2 whose likelihood of commission is $60 \%$ merely shifts the scene of crime and makes good use of resources. In probabilistic terms, there was a significant likelihood of $40 \%$ that D1 would actually have committed crime (say, rape); and as we shall see below, police action could have changed this likelihood either way. Yet even if police action raised the probability of commission, it is hard to say that it caused the commission and wasted resources when stopping D1 from committing the rape in an uncontrolled environment. There was also a significant likelihood of $40 \%$ that D2 would not have committed his crime, and as we shall see below, police action probably reduced this likelihood - which makes it hard to say that they merely shifted the scene of crime. In other words, the $50 \%$ point has no special probabilistic significance which might provide foundation for the 'causing crime' - 'shifting scene' distinction.

These conclusions will not change if it is assumed that the 'likelyunlikely' binary represents more extreme probabilities such as $80 \%$ and $20 \%$. First, such an assumption would not allow determining the legitimacy of many cases of entrapment where the probability of commission absent the entrapment is milder (between 20\% and $80 \%){ }^{19}$ Second, even under this assumption crime is never merely

\footnotetext{
${ }^{18}$ See Becker, no. 12 above.

${ }^{19}$ Unless it is assumed that the hypothetical commission should be proven beyond reasonable doubt; but this too raises difficulties - see discussion in this part, Section E.
} 
relocated - the probability of commission (and thus D's punishment expectancy) can still be raised following police intervention even for $\mathrm{D}$ whose prior likelihood of commission is $80 \%$; and this possible increase in D's punishment expectancy beyond the normal and presumably optimal punishment expectancy is still hard to justify. It is surely not justifiable on the sole basis that the original punishment expectancy is relatively high. ${ }^{20}$ The fact that the punishment expectancy is high cannot suggest that it is suboptimal.

Posner's analysis thus conceals the probabilistic nature of its underlying distinctions, or at least does not endow it with its due analytic significance. What Posner's analysis does not show is that for each defendant there is a different likelihood of commission prior to police action, and further that police action always changes this likelihood - even for defendants whose likelihood of commission is in the extremes. Thus, police action never (or at least hardly ever) affects merely the timing and location of crime. It is always (or almost always) a contributing factor affecting the decision to commit crime.

Furthermore, Posner's analysis does not take into account some of the differences between professional criminals and law-abiding citizens. When Posner suggests focusing only on police action (whether they used powerful threats or promises) and not on defendants' characteristics (which can be somewhat inaccurately described as their 'predisposition, ${ }^{21}$ ), he fails to account for the fact that professional criminals might actually refrain from crime in the face of a particularly strong inducement that would have worked on a more naïve law-abiding citizens. ${ }^{22}$ Considering these difficulties, it seems impossible to base the distinction between legitimate and illegitimate entrapment on Posner's rationale.

\footnotetext{
${ }^{20}$ It is arguable that while the probability of commission and the harm expectancy are high, the punishment expectancy might still be relatively low, at least in certain offences in the context of which entrapment is often deployed. This argument is discussed in Part I, Section E.

${ }^{21}$ Dworkin notes that 'The issue of predisposition, which runs through the entrapment commentary, is a red herring.' Dworkin, no. 1 above, at 29. For Dworkin, 'We are not interested in the general willingness of an offender to commit crime but in whether he has formed the intent to engage in a specific crime if the opportunity presents itself.' (ibid.).

${ }^{22}$ Miceli captures this by demonstrating the deterring effect of police sting operations on professional criminals (no. 13 above).
} 


\subsection{Fairness and Coherence}

Gerald Dworkin presents a different analysis of entrapment law - an analysis whose principles have found expression also in Andrew Ashworth's account of entrapment. ${ }^{23}$ Dworkin draws a distinction between inviting or encouraging crime, and providing an opportunity to commit crime (where 'providing opportunity' is defined narrowly to capture only very laid back practices of the police). ${ }^{24}$ The second is always legitimate; and the first is only legitimate if the police have a probable cause to suppose that $\mathrm{D}$ is already engaged in this kind of crime. ${ }^{25}$ Dworkin grounds these distinctions in considerations of fairness and conceptual coherence of the criminal justice system: the system cannot forbid and then encourage committing that which it forbids, unless the intent to commit such crimes if the opportunity presents itself has already been formulated. ${ }^{26}$ Thus, much police proactive action is presumed to have normative significance.

Dworkin's analysis seems at first sight to acknowledge the probabilistic nature of the question of entrapment. In his argumentation, Dworkin states briefly that both providing an opportunity to commit crime and encouraging crime increase the probability of commission, and hence 'some may regard [the distinction] as hairsplitting'. ${ }^{27}$ But for him, increasing probability of commission does not always require justification; presumably, in the case of opportunity-provision, it does not. To advance this argument, Dworkin notes that shifting police forces from one area to the other would lead to increased probability of crime in the first, yet it does not require justification. ${ }^{28}$ Increasing the probability of commission requires justification where the point of police action is to increase this probability. ${ }^{29}$ Yet this does not seem to resolve the problem, since both when the police merely create opportunities and when they encourage crime, the point of their action is to have someone fall in this or the other trap, or to increase the probability of crime commission. If this is the case, then

\footnotetext{
${ }^{23}$ Ashworth, 'Re-Drawing the Boundaries of Entrapment', no. 7 above, 163.

${ }^{24}$ Dworkin, 'The Serpent Beguiled Me and I Did Eat', no. 1 above, 27.

${ }^{25}$ Dworkin, 'The Serpent Beguiled Me and I Did Eat', no. 1 above, 33.

${ }^{26}$ Dworkin, 'The Serpent Beguiled Me and I Did Eat', no. 1 above, 32-34.

${ }^{27}$ Dworkin, 'Ethics and Entrapment', no. 1 above, 58.

${ }^{28}$ Dworkin, 'The Serpent Beguiled Me and I Did Eat', no. 1 above, 26; Dworkin, 'Ethics and Entrapment', no. 1 above, 58.

${ }^{29}$ Dworkin, 'The Serpent Beguiled Me and I Did Eat', no. 1 above, 26.
} 
the question remains: what does the distinction between providing an opportunity and encouraging or inviting crime rest on?

Furthermore, Dworkin's analysis then goes back to the assumption that in some cases the police do not raise the probability of commission, and that in these cases entrapment is legitimate. $\mathrm{He}$ explains the difference between $\mathrm{D}$ who is already engaged in crime (and hence it is legitimate for the police to invite or encourage her to commit crime) and other Ds who are not engaged in crime (and hence it is illegitimate to invite or encourage them to commit crime). Referring to offers to commit crime addressed to those already engaged in similar crimes, he says: 'Leaving aside complications... such offers are on the portion of the spectrum closer to shifting the scene of criminal activity; ${ }^{30}$ and accordingly they are legitimate. Referring to offers addressed to Ds who are not already engaged in crime, he states: 'In such cases there is the danger that one may not merely shift the scene of criminal activity but create crime that otherwise would not have occurred; ${ }^{31}$ and accordingly such encouragement is illegitimate. Both these contentions regress towards a distinction which is founded on the familiar 'shifting the scene' criterion, whose underlying assumption is that in some cases police activity does not change the probability of crime commission. And if this is the case, Dworkin's distinctions and their proposed rationale are similar in this respect to Posner's ones.

\subsection{Probabilistic Analysis: Police Action Doesn't Merely Shift the Scene of Crime}

Any temptation or opportunity to commit crime presented by the police changes the likelihood of $\mathrm{D}$ committing crime. This is true whether $\mathrm{D}$ has had a pre-existing predisposition towards committing crime or has been a law-abiding citizen; and it is true whether the temptation or opportunity presented by the police is exceptional or just the kind of opportunity D has every day. Accordingly, proactive policing can never be said to merely shift the scene of crime, and it cannot be justified with reference to the cost-effectiveness, to the fairness, or to the coherence of shifting the scene of crime.

To advance this argument, the following analysis uses different methods to examine two reference classes: the class of law-abiding citizens and the class of 'predisposed defendants'. It is presumed that

\footnotetext{
${ }^{30}$ Dworkin, 'The Serpent Beguiled Me and I Did Eat', no. 1 above, 27.

${ }^{31}$ ibid.
} 
'predisposed defendants' are either professional criminals or defendants who were looking for an opportunity to commit crime. ${ }^{32}$ Either way, they would be exposed to relatively many opportunities to commit crime (since they seek for such opportunities, and some will be living in areas which are not crime-free). The 'law-abiding' citizens might or might not be exposed to many opportunities to commit crime - depending on the type of crime (shop-lifting or drug dealing) and on the area where they live (often it would be crime-free, but sometimes it would not). For each of these reference classes, the impact of strong and exceptional inducements and the impact of weak and unexceptional inducements are observed. It should be noted, though, that the division to two reference classes is artificial: actually, there is a spectrum of reference classes between the two extremes identified above (some people are more prone to lawbraking than others). Yet focusing on the two extremes shows that proactive policing changes the likelihood of commission across the entire spectrum of reference classes.

Simple probabilistic analysis is first used to examine the impact of entrapment on the expectancy of crime per time unit (say, a day or a year). Next, Bayes's Theorem is used to examine the impact of entrapment on the probability of crime commission per opportunity to commit crime; and a brief Bayesian analysis of the impact per time unit is then provided - mainly to identify the narrow group of cases in which the impact per time unit diverges from the impact per opportunity, and to explain the significance of this divergence.

Conceptually, the expectancy of crime per time unit is of particular interest for economic analysis of the law, and the probability of crime commission per opportunity is of particular interest for justice-based analysis. Economic analysis aims to adopt strategies which reduce social costs over time, while justice-based analysis seeks to maintain justice or fairness for D over each encounter with the police. Yet the two likelihoods are strongly connected: in the vast majority of cases, where one is increased following entrapment, the other is also increased, and vice versa. There are two reasons for examining both likelihoods: first, as already implied, they are not always directly correlated, and in some cases the expectancy of crime per time unit

\footnotetext{
${ }^{32}$ The literature has attributed significance to the difference between the two and also to some other variants between the professional criminal and the law abiding citizen. See Redmayne's discussion, no. 8 above, especially 166-168. The difference is of lesser significance for the purposes of the current investigation, which focuses on the likelihood of similar commission.
} 
may increase even though the probability of commission per opportunity decreases. ${ }^{33}$ In these cases, economic analysis may diverge from justice-based analysis. Second, each of the examinations puts the spotlight on different factors affecting the probability of commission following entrapment; together, they provide a full picture of the various relevant factors.

\subsubsection{Simple Probabilistic Analysis}

One way of showing the probabilistic implications of entrapment is by using simple probabilistic calculation to examine the changes in the likelihood of crime commission per time unit following entrapment (or the changes in crime expectancy following entrapment) changes which are particularly relevant for an economic analysis of the law.

When it comes to the class of law-abiding citizens, the analysis seems straightforward: we can mark the expectancy of crime commission by a law-abiding citizen over a year as $\mathrm{E}$; and then $\mathrm{E}=\mathrm{N} * \mathrm{P}$, where $\mathrm{N}$ is the number of opportunities to commit crime that the citizen encounters over a year and $\mathrm{P}$ is the probability of actually committing crime each time an opportunity arises. The presence of an undercover police officer who provides an opportunity to commit crime increases $\mathrm{N}$ (creates an additional opportunity to commit crime), and depending on the strength of the inducement, it might also increase $\mathrm{P}$. Thus, the presence of the undercover would increase $\mathrm{E}$, as presumed by existing accounts of entrapment law.

Let us now look at the reference class of the predisposed defendants (or professional criminals). If the crime expectancy for a drug dealer on a day is $\mathrm{E}$, then $\mathrm{E}=\mathrm{N}^{*} \mathrm{P}$, where $\mathrm{N}$ is the number of opportunities the dealer encounters during the day (the number of customers he meets) and $\mathrm{P}$ is the probability of actually making a sale. Here too, the presence of police undercover 'customers' may well increase $\mathrm{N}$ (now there are more customers than before). ${ }^{34}$ We cannot know for sure, however, how it affects $\mathrm{P}$ - this will depend on the deterring effect of proactive policing (does it also cause criminals to refrain from crime) and on the effectiveness of undercover operations. As for the last, if the undercovers are more effective than other

\footnotetext{
${ }^{33}$ Namely where the police raise significantly the number of opportunities.

${ }^{34}$ See also Miceli, no. 13 above, which analyses the situation using conditional probability. Yet as we shall see below, there may be cases in which $\mathrm{N}$ is not increased. Bayesian analysis will show that in these cases too, the likelihood of commission will often increase.
} 
customers in bringing about sales, their presence will increase $\mathrm{P}$ as well, and then the overall crime expectancy will surely increase. If the undercovers are as effective as other customers, their presence will not change $\mathrm{P}$, but since $\mathrm{N}$ is increased, the overall crime expectancy is still increased. And if the undercovers are less effective than other customers, their presence will reduce $\mathrm{P}$, and the implications on the overall expectancy of crime will then depend on the extent to which $\mathrm{N}$ has been increased and the extent to which $\mathrm{P}$ has been decreased (so the overall expectancy might increase, decrease, or stay the same). It can already be noted here that police effectiveness does not necessarily correlate with the strength of the inducement they offer: too strong an inducement might raise the professional criminal's suspicion and actually decrease the probability of commission. ${ }^{35}$

Yet even if it is accepted that the increase in $\mathrm{N}$ (the number of opportunities) affects the expectancy of crime commission, it could be argued that more often than not $\mathrm{N}$ cannot be changed, simply because the defendant has as many opportunities to commit crime as he can take (there is more demand for drugs than the drug dealer can supply). Thus, the defendant will effectively have, say, 10 opportunities to commit crime per day with or without the additional opportunities provided by the police. Here, Bayes's Theorem becomes a more effective tool of demonstrating the effects of proactive policing.

\footnotetext{
${ }^{35}$ Thomas Miceli has already used simple probabilistic tools in his economic analysis of the law of entrapment. (Miceli, no. 13 above). He realizes that much police pro-active action increases crime expectancy, but he seeks to distinguish legitimate from illegitimate increases by distinguishing the allegedly legitimate increase in $\mathrm{N}$ from the illegitimate increase in $\mathrm{P}$. It is unclear why the enforcement costs which $\mathrm{D}$ creates can be legitimately minimized by increasing D's crime expectancy through addition of opportunities but not through provision of a stronger inducement to commit crime. Furthermore, Miceli's analysis relies on a sharp distinction between those who have decided to commit an offence (and hence create enforcement costs) and those who have not, but it is doubtful whether this distinction accords with reality. In reality, there are different levels of readiness to commit crime, and accordingly different levels of resulting enforcement costs. Last, Miceli's analysis renders sweeping conclusions with respect to the implications of entrapment for the likelihood of crime commission (i.e. the likelihood of commission is always increased following entrapment because of the increase in $\mathrm{N}$ ). This analysis does not take count of a range of factors which might affect and change the likelihood of commission following entrapment.
} 


\subsubsection{Bayes's Theorem ${ }^{36}$}

Bayes's Theorem is another tool which demonstrates that police proactive action does not merely shift the scene of crime. It does, in fact, change (and often increases) the likelihood of crime commission. In addition, Bayes's Theorem can be used to calculate changes in the probability of crime commission per opportunity to commit crime (rather than the expectancy of crime per time unit). These changes are of particular interest for a justice-based analysis of the law; they usually - though not always - correlate with the changes in the expectancy of crime per time-unit which are more relevant for an economic analysis of the law. When Bayes's Theorem is used in this way, it reveals all the range of factors affecting the changes in the likelihood of commission following entrapment, thus demonstrating the limited significance of changes in the number of opportunities, and also the difficulty in evaluating the changes in probability for any given case. Bayes's Theorem can then be used to examine the changes in the expectancy of crime per time unit following entrapment, thus revealing a small group of cases in which a justice-based analysis could potentially have diverged from an economic analysis. For these reasons, it is a beneficial tool for the purposes of the current investigation.

I have explained elsewhere how Bayes's Theorem works. ${ }^{37}$ For current purposes, we can proceed directly to explaining how it would work in the context of entrapment. We can define an opportunity to commit crime as 'an encounter'. Assume now that $\mathrm{P}(\mathrm{E} \mid \mathrm{C})$ is the probability that a given encounter in which the defendant has committed crime is with an entrapping undercover, and $\mathrm{P}\left(\left.\mathrm{E}\right|^{\wedge} \mathrm{C}\right)$ is the probability that a given encounter in which the defendant has not

\footnotetext{
${ }^{36}$ Bruce Hay has used Bayes's Theorem to discuss a different question in the context of entrapment (Bruce Hay, 'Sting Operations, Undercover Agents, and Entrapment', (2005) 70 MLR 387). For Hay, entrapment is justified when it provides the criminal justice system with accurate information on whether $\mathrm{D}$ is a criminal, or was D likely to have committed similar crimes absent police interventions. Bayes's Theorem is used to identify the likelihood that given the fact that D was entrapped, $\mathrm{D}$ would have committed similar crimes absent police intervention (see especially pp. 404-409). Thus, the legitimacy of entrapment is examined based on a parameter which is similar to the one suggested by Posner, and the difficulties it raises were discussed above. This parameter assumes that if $\mathrm{D}$ was sufficiently likely to have committed similar crimes absent police intervention, entrapment is justified; but it does not explain how the higher likelihood of crime commission justifies increasing this likelihood even further.

${ }^{37}$ Liat Levanon, 'Sexual History Evidence in Sexual Assault Cases: A Critical Reevaluation', 64 (2012) University of Toronto Law Journal 609 at 365.
} 
committed crime is with an entrapping undercover. The term $\mathrm{P}(\mathrm{E} \mid \mathrm{C}) /$ $\mathrm{P}\left(\mathrm{E} \mid{ }^{\wedge} \mathrm{C}\right)$ is called 'the likelihood ratio'. The likelihood ratio for a specific case of entrapment tells us whether entrapment has increased or decreased the odds of the defendant committing the crime compared to the average odds of commission, and by how much. The question whether the odds of commission have increased or decreased is determined by comparing the two abovementioned probabilities (which one has higher value). The question by how much the odds have changed is determined by dividing the two probabilities. ${ }^{38}$

In simple terms, the Theorem works as follows: First, the prior odds of commission are calculated (the odds that a random person commits crime, regardless of police action). The prior odds of commission are calculated by way of tracing the relevant class of persons (in our case, predisposed defendants and law-abiding citizens) and then dividing the probability of commission within this class by the probability of non-commission within it. This ratio will be termed Q. Next, the inducing power of entrapment is calculated. The inducing power of entrapment is reflected in the abovementioned likelihood ratio. Assuming we can calculate the likelihood ratio, we can now say what the 'posterior odds of commission' in a given case are (i.e., the odds of commission given the entrapment) and compare them with $\mathrm{Q}$ (the prior odds of commission) to see by how much they have changed.

The proposed argument focuses on the likelihood ratio in order to determine whether entrapment increases the likelihood of commission. Focusing on the likelihood ratio, it is evident that entrapment would tend to increase the odds of commission if the probability of tracing it is higher assuming that crime was committed. Only in this case, the likelihood ratio of entrapment would tend to increase the odds of commission. We should therefore ask which of the two probabilities is higher.

\footnotetext{
${ }^{38}$ Another way of working with the Theorem in this context is looking at $\mathrm{P}(\mathrm{C} \mid \mathrm{E}) /$ $\mathrm{P}\left(\left.\mathrm{C}\right|^{\wedge} \mathrm{E}\right)$. Only where this value is equal to or smaller than 1, entrapment does not increase the likelihood of commission per opportunity. According to the Theorem, $\mathrm{P}(\mathrm{C} \mid \mathrm{E})=(\mathrm{P}(\mathrm{E} \mid \mathrm{C}) * \mathrm{P} 0(\mathrm{C})) / \mathrm{P} 0(\mathrm{E})$, where $\mathrm{P} 0$ stands for prior probabilities. In addition, $\left.\mathrm{P}\left(\mathrm{C} \mid{ }^{\wedge} \mathrm{E}\right)=\mathrm{P}\left({ }^{\wedge} \mathrm{E} \mid \mathrm{C}\right) * \mathrm{P} 0(\mathrm{C})\right) / \mathrm{P} 0\left({ }^{\wedge} \mathrm{E}\right)$. If we divide the two, we get $\mathrm{P}(\mathrm{C} \mid \mathrm{E}) / \mathrm{P}\left(\left.\mathrm{C}\right|^{\wedge} \mathrm{E}\right)=$ $\left(\mathrm{P}(\mathrm{E} \mid \mathrm{C}) * \mathrm{P} 0\left({ }^{\wedge} \mathrm{E}\right)\right) / \mathrm{P}\left({ }^{\wedge} \mathrm{E} \mid \mathrm{C}\right) * \mathrm{P} 0(\mathrm{E})$. And so, $\left(\mathrm{P}(\mathrm{E} \mid \mathrm{C}) / \mathrm{P}\left({ }^{\wedge} \mathrm{E} \mid \mathrm{C}\right)\right)^{*}\left(\mathrm{P} 0\left({ }^{\wedge} \mathrm{E}\right) / \mathrm{P} 0(\mathrm{E})\right)<1$ where $\mathrm{P}(\mathrm{E} \mid \mathrm{C}) / \mathrm{P}\left({ }^{\wedge} \mathrm{E} \mid \mathrm{C}\right)<\mathrm{P} 0(\mathrm{E}) / \mathrm{P} 0\left({ }^{\wedge} \mathrm{E}\right)$. This means that entrapment would not increase the odds of commission per opportunity only where the portion of crimes detected through entrapment is smaller than the portion encounters which are entrapments. It can be shown that this condition hardly ever exists, and that in any case it is very hard to know if it exists in a given case.
} 
Here too, we should first identify a relevant reference class. Next, we should model assessments of the inducing value of entrapment, examining different types of entrapment and different strengths of inducement (such as entrapments providing exceptionally attractive opportunities to commit crime or entrapments providing a normal opportunity to commit crime).

\subsubsection{The Reference Class of 'Law-Abiding Citizens'}

We can begin by showing briefly and informally that, as assumed by existing accounts of entrapment, where the reference class is defined as 'non-predisposed' or law-abiding defendants, then at least under some limiting assumptions regarding the prevalence of opportunities to commit crime entrapment would often increase the probability of commission, and it would probably increase this probability proportionately to the strength of the inducement presented.

Let us assume that the police deploy successful random entrapment in 2 out of 10 commissions by non-predisposed citizens. The probability of entrapment assuming commission would be 0.2 .

Now we have to compare the above probability with the probability of entrapment assuming a decision not to take an opportunity to commit crime. Let us assume here that the non-predisposed citizen encounters a significant number of opportunities to commit the relevant crime (say, to shoplift, to rape, or to purchase some drugs). ${ }^{39}$ Such a citizen makes many 'no commission' decisions every day - the vast majority of which are taken without entrapment in the background, and a small minority of which are taken on the background of entrapment. Hence the probability of tracing entrapment in cases of 'no commission' decision is fairly low - it may well be lower than 0.2 . In such cases, entrapment increases the probability of commission.

This analysis further suggests that the increase in the probability of commission following entrapment will be higher the more effective

\footnotetext{
${ }^{39}$ Squires (supra no. 3) assumes that law abiding citizens do not encounter many opportunities to commit crime. He further assumes that when encountering such opportunities, law abiding citizens would tend to take them. This leads him to criticize the law which often prohibits entrapment of law abiding citizens. However, probabilistic analysis would demonstrate that under these assumptions, entrapment may or may not increase the likelihood of commission; and that the only assumptions under which we can be sure that entrapment does not increase the likelihood of crime is that law abiding citizens would tend not to take such opportunities (in contrast with Squires' assumptions).
} 
the police are, or the stronger or more exceptionally attractive the inducement is. The more exceptionally attractive the inducement the police offer, the more cases will there be of tempted citizens, and so (1) the likelihood of tracing entrapment assuming commission would increase; and (2) the likelihood of tracing entrapment assuming noncommission would decrease, since there would be hardly any "no commission' decisions taken on the background of entrapment (as the inducement will bring about a 'yes' decision). Thus, if the inducement is particularly strong, the probability of tracing entrapment where a decision not to commit is taken might become very low. Accordingly, in such cases entrapment raises the probability of commission even further.

If this analysis is correct, then the law's prohibition on entrapment of non-predisposed, law-abiding citizens seems justifiable in terms of cost-effectiveness and of fairness: it is not cost-effective and also unfair to raise the probability of a citizen committing crime, and then to sanction her for the commission.

\subsubsection{The Reference Class of 'Predisposed Defendants'}

We can now examine a different reference class, namely the reference class of predisposed or 'ready to commit crime' defendants. Let us look at the likelihood ratio in this case:

First, we have to calculate the likelihood of entrapment assuming commission. We can assume, for the purposes of providing a starting point, that the police deploy successful targeted entrapment (successful entrapment of predisposed Ds) in 3 of 10 cases of commission by such Ds. In that case, the probability of entrapment assuming commission would be $3 / 10$ or 0.3 .

Now we have to compare the above probability with the probability of entrapment assuming a decision by the predisposed offender to skip an opportunity to commit crime. Here, modelling the relevant assessments would be more difficult, as the assessments are harder to make. The probabilities of entrapment in cases of a decision to refrain from crime commission can range; and they would range regardless of the question whether the defendant is a 'fully occupied' criminal or not. The question concerns the number of decisions to skip an opportunity to commit crime which were actually unsuccessful entrapments. This figure is unknown, and various estimations are plausible. Estimating that 1 in 10 non-commissions by predisposed offenders are unsuccessful entrapments could be just as plau- 
sible as assessing that 5 in 10 non-commissions are unsuccessful entrapments. And so, the probability of entrapment assuming noncommission might be higher than the probability of entrapment assuming commission (0.3), or it might be lower than this likelihood. There is hardly ever a way of knowing if entrapment did not increase the probability of commission for the predisposed criminal just the way it increases it for the law-abiding citizen. The only thing that can be said is that the less cautions or hesitant or otherwise reluctant to jump on every opportunity to commit crime $\mathrm{D}$ is, and the more effective the police are, the more likely it is that entrapment indeed increases the probability of commission. ${ }^{40}$ Accordingly, it is impossible to conclude that entrapment of the predisposed criminal is legitimate, or even that entrapment is normally legitimate except for cases where the police are potentially highly effective in bringing about crime, for example because they use excessive inducement. Entrapment may well be illegitimate also where police actions are potentially less effective, but D is insufficiently cautious. Accordingly, entrapment is always at least suspected of increasing the likelihood of commission, even for the professional criminal. Formal analysis could show that it often does increase this likelihood. ${ }^{41}$

This model could be developed further to examine whether entrapment changes the likelihood of commission not per encounter, but per time unit (the crime expectancy). In this case, it would examine the same variable that was examined above using simple probabilistic tools, and which is more relevant for an economic evaluation of the law. Here, Bayesian analysis would show that if entrapment does not increase the number of opportunities to commit crime per time unit (the number of encounters), the likelihood of crime commission per time unit will increase if $\mathrm{P}(\mathrm{C} \mid \mathrm{E})$ is higher than $\mathrm{P}\left(\left.\mathrm{C}\right|^{\wedge} \mathrm{E}\right)$, i.e. if an encounter between $\mathrm{D}$ and the police is more likely to bring about crime than an encounter between $\mathrm{D}$ and other ac-

\footnotetext{
${ }^{40}$ Notably, the level of police activity also affects D's decisions in the same direction: the more active the police are, the more suspicious D would become, and the more opportunities per day he would choose to pass.

${ }^{41}$ For example, where the prior probability of commission is 0.5 , the probability that an encounter is with an undercover is 0.25 , and all entrapments are successful, Bayesian analysis would show that entrapment increases the probability of commission. Where only $60 \%$ of entrapments are successful, as long as D's likelihood of passing an opportunity to commit crime is lower than 0.75 , entrapment would still increase the likelihood of commission.
} 
tors. ${ }^{42}$ If entrapment does increase the number of encounters per time unit, then the likelihood of crime commission per time unit may increase even if $\mathrm{P}(\mathrm{C} \mid \mathrm{E})<\mathrm{P}\left(\left.\mathrm{C}\right|^{\wedge} \mathrm{E}\right)$ - i.e. even if an encounter between $\mathrm{D}$ and the police is less likely to bring about crime than an encounter between $\mathrm{D}$ and other actors. ${ }^{43}$

Thus, where the likelihood of crime commission per time unit (or the expectancy of crime) is calculated, additional conclusions which may be relevant for economic evaluation of the law are revealed. Here too, in most cases entrapment would increase the expectancy of crime, and the rare cases in which it would not increase the crime expectancy are hard to identify in advance since their determining characteristics are contingent (police effectiveness and defendant's tendency to skip opportunities to commit crime). Under some very limiting conditions, which are not identified by existing law and are indeed hard to identify in advance, entrapment may be legitimate from an economic perspective (in addition to a justice perspective, as identified above). This would be the case where entrapment increases neither the number of opportunities to commit crime nor the likelihood of commission per opportunity (taking into consideration the factors mentioned above). More importantly, the analysis per time unit also indicates that there is a narrow group of cases where entrapment might be illegitimate from an economic perspective, even though it is legitimate from a perspective of justice. This would be the case where entrapment increases the number of opportunities to commit crime so significantly that even given a decrease in the probability of commission per opportunity (taking count of the factors mentioned above), the likelihood of commission per time unit would still increase.

\footnotetext{
${ }^{42}$ It is assumed that the encounters are independent from one another (which is normally the case). In a world without entrapments $\mathrm{P} 0(\mathrm{C})=\mathrm{P} 0\left({ }^{\wedge} \mathrm{E}\right)$. We can term this value $\mathrm{X}$. If over a day the drug dealer has 10 successful encounters, his crime expectancy is $10 \mathrm{X}$. Now assume that the police replace 5 of the real encounters. $\mathrm{P} 0(\mathrm{C})$ $=\left(\mathrm{P}(\mathrm{C} / \mathrm{E})+\mathrm{P}\left(\mathrm{C} /{ }^{\wedge} \mathrm{E}\right)\right) / 2$. We can term this value $\mathrm{Y}$. The crime expectancy per day will be $10 \mathrm{Y}$. We should now examine in which conditions $10 \mathrm{Y}$ will be higher than $10 \mathrm{X}$, and it is evident that this will be the case where $\mathrm{P}(\mathrm{C} / \mathrm{E})>\mathrm{P}\left(\mathrm{C} /{ }^{\wedge} \mathrm{E}\right)$.

${ }^{43}$ Assume again like ibid., namely that in a world without entrapments $\mathrm{P} 0(\mathrm{C})=\mathrm{P} 0\left({ }^{\wedge} \mathrm{E}\right)=\mathrm{X}$; and then that the drug dealer has 10 successful encounters per day, and his crime expectancy is $10 \mathrm{X}$. Now assume that the police add 5 further encounters. If, say, only one of these encounters is successful, it is possible that police activity would decrease the probability of commission per opportunity, yet it would still increase the probability of commission per time unit (since there is one additional commission).
} 
We can now examine whether the power of the threat or promise offered by the police plays a role in this analysis. The nature of the inducement is one non-determinative factor affecting the outcomes of the analysis. The assumption underlying the law of entrapment is that the stronger and more exceptional the inducement police offer, the more effective police action is in bringing about crime commission, and the less legitimate the entrapment is. There is, however, good reason to assume that at least as far as the professional or experienced criminal is concerned, police action would be effective where the police best imitate the normal settings of crime, or merely provide a normal opportunity to commit crime; and it would be less effective where the police offer incentives which are stronger than normal hence raising the experienced criminal's suspicion and leading her to refrain from crime commission. Accordingly, there is reason to think that police action changes the likelihood of crime in a way different to the one assumed by the literature and the courts: when providing normal opportunity for the predisposed criminal, it actually raises the likelihood of him committing the offence, and hence this is the case in which the legitimacy of police action should be put in question. Clearly, such a hypothesis requires empirical support. Yet in the absence empirical research, the least that can be said is that we do not know that this hypothesis is any weaker than the other hypothesis.

To summarize, it is impossible to know how exactly police action affects the likelihood of commission per opportunity or per time unit by the predisposed defendant in any given case; and there is reason to think that the more 'normal' the opportunity provided by the police, the higher the chances that police action actually increased the likelihood of commission per opportunity and per time unit for the predisposed defendant, just the way powerful threats or promises do for the law-abiding citizen.

\subsection{Interim Conclusions}

We have seen that there is no essential connection between D's readiness to commit crime or the exceptionality of the opportunity provided by the police, and the changes in the likelihood of crime commission per opportunity or per time-unit following entrapment. Entrapment potentially increases the likelihood of commission for professional criminals provided with normal opportunity to commit crime as well as for law-abiding citizens provided with exceptional opportunity to commit crime (at least under some plausible 
assumptions). ${ }^{44}$ In the vast majority of cases, this potential increase exists both for the likelihood of commission per opportunity and for the likelihood of commission per time-unit. Accordingly, the distinction between the two classes of defendants and the distinction between the two types of police action cannot be used to differentiate legitimate police operation from illegitimate entrapment on economic grounds or on grounds of justice. A different basis for the differentiation should therefore be sought after. After examining a possible objection to the analysis which has been proposed thus far, the next part of the article will propose such a basis.

\subsection{Possible Objections to Focusing on the Increase in Probability of Crime}

One possible objection is that the increase in the probability of crime commission, and thus also in D's punishment expectancy, is justifiable where immaterial or marginal. Economically, where this increase is low and the decrease in harm expectancy is high, entrapment is justified. In addition, it is just to impose on the defendants marginal burdens to neutralize the risks she poses. Thus, the real question is not whether entrapment increases the probability of commission, but by how much.

One has to distinguish between statistical significance and materiality. It was demonstrated earlier that the likelihood ratio indicates whether entrapment changes the odds of commission: where the probability of tracing entrapment given commission is higher than the probability of tracing entrapment given non-commission (the likelihood ratio is below 1), entrapment increases the odds of commission. Yet not every such increase is to be considered statistically significant: a likelihood ratio which is higher than 0.5 (and lower than 2) is usually considered as indicative of an insignificant change of odds. ${ }^{45}$ Thus, if it could be shown that entrapment increases the odds of commission only insignificantly, the objection would have been valid. This, however, is not the case. As we saw, it is impossible to know the exact value of the likelihood ratio in this context, though there are reasons to think that it is lower than 1, and similarly, it is plausible that it would be lower than 0.5 in some if not in most cases.

\footnotetext{
${ }^{44}$ And it can decrease this likelihood for both classes in some circumstances.

45 The exact values would depend on the question what probability of 'type I error' is considered tolerable (rejection of a null hypothesis that is true, or concluding that entrapment does not increase commission odds where in fact it does).
} 
But the objection goes further than that: it argues that even if the increase in the odds of commission is probabilistically significant, it is still often too small to have normative significance. This objection gives rise to several difficulties. First, the assumption that small increases are justifiable and high increases are unjustifiable is not valid. In some cases it seems justifiable to increase the probability of commission significantly through entrapment. For example, entrapment of a potential murderer whose likelihood of commission is $35 \%$ seems justifiable even if it increases the probability of commission to $80 \%$ (assuming that there are no other means to prevent him from murdering). In the same manner, entrapment sometimes seems unjustifiable even where the increase in the probability of commission is low. For example, inducing tax evasion seems fairly objectionable even where the inducement does not raise the probability of commission significantly.

Second and relatedly, the increase in probability might be high even for the professional criminal who encounters many opportunities to commit crime, since, for example, he might be a picky or hesitant criminal who takes only a small portion of the many opportunities available to him. In other words, the question whether the increase in probability is material can only be determined in the context of the specific offender-police relation, and it would be affected by characteristic of the particular offender and of the particular police undercover (how effective she is). Accordingly, ensuring that the increase in the probability of commission is immaterial is difficult both prospectively and retrospectively. In such conditions, there are reasons to assume in favour of the defendant that the increase is material.

Third, this line of argument does not take into account the preexisting correlation between crime expectancy and punishment expectancy. This prior correlation is supposed to be cost-effective and just. Entrapment increases the punishment expectancy beyond the level which is supposed to be cost-effective and just, and it does so without explaining why this level is actually not cost-effective or unjust in the relevant case. Thus, the objection is counter-intuitive and presumes that which requires explanation.

It could also be argued that the question is not whether the police increased the probability of commission, but whether this probability was high enough even absent police intervention. According to this line of argument, the law of entrapment should direct the fact finder to find out whether it is possible to be convinced beyond reasonable doubt that $\mathrm{D}$ would have committed a similar offence absent police intervention (the hypothetical offence); or in other words, the fact finder has 
to determine whether the probability of $\mathrm{D}$ having committed the hypothetical offence meet the 'beyond reasonable doubt' standard. If the answer is in the positive, entrapment would be deemed legitimate: the difference between the actual entrapment-offence and the hypothetical offence becomes normatively insignificant, and we can think of the hypothetical offence as having been committed beyond reasonable doubt (or to import the actuality of the entrapment-offence to the platform of the hypothetical offence). If the answer is in the negative, entrapment would be illegitimate, as we cannot think of the hypothetical offence as having been committed beyond reasonable doubt (or import the actuality of the entrapment offence to the platform of the hypothetical offence). Accordingly, existing legal distinctions cannot be criticized on the basis that they fail to account for the increased probability of commission in all cases of police intervention.

If this understanding is taken on board, existing law can be justified on the following lines: the courts actually seek to establish the probability of commission absent police interference; and they do so by reference to D's predisposition, to the strength of the inducement, or to the exceptionality of the opportunity offered by the police. All of these tests reflect the valid assumption that if the settings remain the same, people would tend to repeat some courses of conduct in very high likelihood ${ }^{46}$ (or, presumably, beyond reasonable doubt); thus those who are used to committing crime in certain settings would repeat this conduct in the same settings in very high likelihood; and those who do not commit crime in normal settings would in very high likelihood not commit crime as long as the settings are not changed. Accordingly, the first should be found guilty, and second - not guilty. Under these assumptions, existing law makes good sense.

${ }^{46}$ The assumption of repetition is widely accepted amongst researchers of human psychology. According to this assumption, a combination of personal and situational factors would lead to repetition of some courses of conduct. The relative weight of personal and situational factors in causing action might change, and some people tend to attune their conduct to the situation more than others, but a well-defined rule of repetition can still be identified. See e.g. Paul L Wachtel, 'Psychodynamics, Behavior Therapy, and the Implacable Experimenter: An Inquiry into the Consistency of Personality' (1973) 82(2) Journal of Abnormal Psychology 324; Mark Snyder, 'SelfMonitoring Processes', in L Berkowitz, ed, Advances in Experimental Social Psychology (New York: Academic Press, 1979), vol 12 at 85; Daryl J Bem \& Andrea Allen, 'On Predicting Some of the People Some of the Time: The Search for Cross-Situational Consistencies in Behavior' (1974) 81(6) Psychological Review 506; Leonard Berkowitz, Aggression, Its Causes, Consequences, and Control (New York: Mcgraw-Hill, 1993) 128-9; Norman S Endler \& J McVicker Hunt, 'Triple Interaction Variance in the S-R Inventory of Anxiousness', (1968) 27 Perceptual and Motor Skills 1098. 
But only just so. First, because there are good and familiar reasons not to convict based on the assumption of repetition, ${ }^{47}$ the main of which are the biasing effect of this assumption, and the lack of incentive for 'predisposed' defendants to refrain from crime if convictions can be based on this assumption. ${ }^{48}$ Second and relatedly, it is unclear that the assumption of repetition is indeed so strong, namely that people repeat courses of conduct at such a high probability that it meets the 'beyond reasonable doubt' standard (but at the same time we do know that fact finders might give exaggerated weight to the assumption of repetition). Third, there is a difficulty in convicting based on integration of a fictional offence with a real one. We know that the fictional offence is, as the case is, fictional. We know that it has not been committed, though its probability of commission allegedly crossed the criminal threshold. The beyond reasonable doubt' standard is supposed to establish knowledge (of beyond reasonable doubt) that an offence was committed. Where it cannot establish such knowledge, and the case remains one of a theoretical probability that has not been actualized, the beyond reasonable ground' standard is an insufficient ground for conviction - with or without the actuality of a different offence. Accordingly, this line of argument does not provide foundation for determining the legitimacy of entrapment based only on the likelihood of similar crime commission absent entrapment.

\section{PART II: A POSSIBLE FOUNDATION FOR A LAW OF ENTRAPMENT}

\subsection{Burdens and Their Reallocation}

Offenders create risks for, and place burdens on, their victims and on general society. The law designs mechanisms which ensure that the burdens offenders create are justly reallocated. This normally entails

\footnotetext{
${ }^{47}$ For a comprehensive account of possible justifications for the regulation of the introduction of 'character evidence' demonstrating past similar conduct see David P. Leonard, 'In Defence of the Character Evidence Prohibition: Foundations of the Rule against Trial by Character', (1997-1998) 73 Indiana Law Journal 1161.

${ }^{48}$ See Chris William Sanchirico, 'Character Evidence and the Object of Trial', (2001) 101 Columbia Law Review 1227; David Enoch and Talia Fisher, 'Sense and 'Sensitivity': Epistemic and Instrumental Approaches to Statistical Evidence', (2015) 67 Stanford Law Review 585, section III(B).
} 
undoing the burden-imposition at the cost of imposing another burden on the offender which does not exceed the overall original burden the offender had created. ${ }^{49}$ The law sets a range of reallocation mechanisms, including permissions to deploy burdensome preemptive means to prevent commission of offences, permissions to deploy force to stop the commission of offences, and to the extent that punishment is perceived as corrective also permissions to impose criminal sanctions. ${ }^{50}$ The different mechanisms take count of the weight of the burden that requires reallocation. The heavier the burden that the offender creates, the heavier the burden that the law would permit imposing on the offender with the prospect of relieving the original burden.

Burden reallocation is connected, but not identical, to risk management. Risk management theories consider legal rules as mechanisms designed to best manage different social risks. Risk management is considered as morally neutral or as part of a utilitarian ethics; yet it has been criticized for concealing moral premises through the definition and evaluation of risks. ${ }^{51}$ Burden reallocation is neither morally neutral nor utilitarian: it is rooted in distributive justice, and it is the other side of redistribution of resources. ${ }^{52}$ More often than not just redistribution of burdens overlaps with good (and indeed cost effective) risk management, but this is not necessarily the case. Thus, for example, risk management allows for risks of crime to be pushed onto potential victims where this is the most cost-effective

\footnotetext{
${ }^{49}$ See Liat Levanon, "Punishment and Self-Defence: A Comment on Victor Tadros" "The Ends of Harm"”, 5 (2012) JRSLM. REV. LEGAL STUD. 75-88, and compare with Victor Tadros, 'Replies' (Book Symposium on Victor Tadros' The Ends of Harm: The Moral Foundations of Criminal Law) (2012) 5 Jerusalem Review of Legal Studies 89. Another question is whether and how the imposition of criminal punishment can reallocate burdens. An initial solution is indicated in Liat Levanon, 'Criminal Punishment as a Restorative Practice' (2015) 18 New Criminal Law Review 537.

${ }^{50}$ See Liat Levanon, 'Personhoood, Equality, and a Possible Justification for Criminal Punishment' (2014) 27 The CANADIAN JOURNAL OF LAW AND JURISPRUdenCE 439; and Liat Levanon, 'Criminal Punishment as a Restorative Practice', ibid.

${ }^{51}$ For a comprehensive review of risk management and its moral aspects see Richard V. Ericson and Aaron Doyle, Risk and Morality (University of Toronto Press, Toronto, Buffalo, and London: 2003).

${ }^{52}$ See also Levanon, 'Punishment and Self Defense', no. 49 above; and Levanon, 'Criminal Punishment as a Restorative Practice', no. 49 above.
} 
way to prevent crime, ${ }^{53}$ while from the point of view of burden reallocation such a move would be contestable and will require further justification. ${ }^{54}$

The weight of the burden that the offender creates depends on a variety of factors. One such factor is the type of offence (directed at specific victims or victimless). Another such factor is the stage of commission (developing intent and planning the offence, execution, and completion ${ }^{55}$ ). These factors are connected: the exact burdens created at each of these points of the criminal operation would depend on the type of offence. ${ }^{56}$ When it comes to offences directed against victims, the burden created at the pre-completion stages is particularly heavy: where commission has not yet begun, D not only places on $\mathrm{V}$ the offence's harm expectancy, but also puts $\mathrm{V}$ in a position of uncertainty, having to decide of an effective response to

${ }^{53}$ Compare with Alon Harel, 'Efficiency and Fairness in Criminal Law: The Case for a Criminal Law Principle of Comparative Fault' (1994) 82 California Law Review 1181; and Omri Ben Shachar and Alon Harel, 'Blaming the Victim: Optimal Incentives for Private Precautions against Crime', (1995) 11 Journal of Law, Economics, and Organization 434. The authors argue that some burdens are appropriately placed on potential victims (namely where the combination of private protection means with governmental protection means provides optimal enforcement). My argument is that this is only part of the story: optimal enforcement means that the burdens on potential victims are pushed back to the offender, to the extent that it is possible to do so, through these radical governmental or private defensive mechanisms.

${ }^{54}$ Hence, for example, the state cannot oblige home owners to install locks. The argument advanced here is that where a potential victim has been motivated to installing expensive locks, the law should push this burden back to $\mathrm{D}$, for example by being more permissive with respect to entrapment of $\mathrm{D}$ or by punishing $\mathrm{D}$ who broke such a lock more severely than another $\mathrm{D}$ who entered an open door. This argument is consistent with Ben-Shachar and Harel's conclusions with respect to optimal sentencing (ibid.), but for reasons different from the ones they provide.

${ }^{55}$ Different legal mechanisms work to reallocate different burdens created at different stages of the operation. Some of the mechanisms are designed to reallocate the burdens created following the completion of the offence. These include mainly punitive mechanisms (the permission to impose criminal sanctions and sentencing rules and guidelines). Other mechanisms are designed to reallocate the burdens created prior to completion. These are the defensive mechanisms. Substantive criminal law defences such as self-defence and prevention of crime reallocate burdens created during commission but before completion; and public law rules and, to an extent, also rules of evidence regulating police action reallocate burdens created before commission has begun. Considering the fact that the burdens created at different points of the operation are of different weights, each of these mechanisms would permit the imposition of different burdens on D.

${ }^{56}$ See also Levanon, 'Punishment and Self Defence', no. 49 above. 
the threat without knowing the full scope of the threat or indeed the exact likelihood that the threat will materialize. Thus, for example, the to-be-robber imposes on his potential victims the burden of improving their security measures (locks, alarms, etc.), inherent in which is the burden of deciding the extent of such improvements without knowing the exact intentions and capabilities of the robber and when being under stress. The to-be-robber further imposes on his potential victims the burden of considering and deciding on potential self-defensive measures if and when attacked, without knowing the scale of attack she might be facing and the exact likelihood of such attack- should she prepare herself for a physical attack? If so, would arms be involved? Of which types? The burdens that $\mathrm{D}$ puts on $\mathrm{V}$ grow further as D proceeds with his plans and starts the actual commission. The likelihood of commission then grows to a point of almost $100 \%$ (once the robber has entered the bank holding his gun, the likelihood of him withdrawing becomes negligent). In addition, the threat becomes imminent hence requiring quick decision making in conditions of distress and some uncertainty. Once the commission has been completed, the burdens may well decrease: while the likelihood of commission is now $100 \%$, the burdening elements of uncertainty and imminence are no longer present. The extent of the burden involved is already known, and there is no need to decide on preventive response without knowing the extent of the risk and when under stress and time pressures. ${ }^{57}$ Thus, the burden comes only to the offence's harm expectancy. To conclude, when it comes to offences against victims, the burdens $\mathrm{D}$ puts on $\mathrm{V}$ in the pre-completion stages go beyond the offence's harm expectancy; after completion, these burdens decrease.

Things are different when it comes to victimless offences (offences against the public or the environment, or offences committed by two consenting parties). Here, the burdens that D places on others in the pre-completion stages are lower. D does not put anyone in the difficult position of the attacked victim with all the implications of this. Accordingly, the burden D creates before and during commission is composed mainly of the offence's harm expectancy. This burden is close to the burden created following completion, with the only difference being in the likelihood of completion which is certain only

\footnotetext{
${ }^{57}$ Considering this decrease in burdens, the permitted punitive response would hardly ever be as weighty as the permitted defensive responses. See Levanon, 'Punishment and Self Defense', no. 49 above.
} 
post-completion. Thus, in victimless offences the burdens $\mathrm{D}$ creates come only to the offence's harm expectancy.

\subsection{Entrapment and Self-Defence: Burden Reallocation Prior to Completion}

The law of entrapment works prior to and throughout the commission of the offence. Accordingly, it is a defensive mechanism which works at the pre-completion stages of the criminal operation, and it is comparable not only to rules regulating police action, but also to substantive defences. Specifically, entrapment and self-defence have similar theoretical foundations.

Leo Katz has already noted the similarities between the two. ${ }^{58} \mathrm{His}$ analysis is based on the actio libera in causa doctrine, and it focuses on comparison between provoked self-defence and illegitimate entrapment. Katz notes that '[a]ctually private entrapment, as illustrated by provocation self-defence, and governmental entrapment are treated analogously provided one knows what to look for. Situations in which the motivations of a private entrapper are exactly like those of the government are treated in exactly the same way'. ${ }^{59}$ Katz's analysis leads him to compare the loss of the self-defence defence following provocation to the loss of 'the defence [the government] is usually able to make for putting someone in jail, namely that he deserved it'. ${ }^{60}$ The analogy seems to require further elucidation with respect to the way desert works as a defence for the government's punitive act. But the analogy between entrapment and self defence is nevertheless a valid analogy, and it can be based on different grounds.

Self-defence and entrapment are defensive mechanisms that negate the liability of actors (the victim or the police undercover) for burdens they impose on others (the attacker or the entrapped defendant). When self-defense or entrapment are used, the outcome for those against whom they are used might be mitigation of sentence - either personal mitigation for the attacker who was badly hurt by her victim's self-defensive act, or general mitigation for the defendant who fell for the police's entrapment.

Since entrapment and self-defence are both defensive reallocation mechanisms, they should be designed according to the same princi-

\footnotetext{
${ }^{58}$ Leo Katz, 'Entrapment through the Lens of Actio Libera in Causa', (2013) 7 Criminal Law and Philosophy 587.

59 ibid. at 595.

${ }^{60}$ ibid.
} 
ples. Both mechanisms are aimed at neutralizing the risks D creates prior to completion of the offence at the price of placing burdens on $\mathrm{D}$ which do not exceed the original risks D created. Accordingly, both mechanisms have to reflect the reallocation of not only the offence's harm expectancy, but also any additional burdens D creates prior to completion, if there are such additional burdens. The exact nature of the additional burdens might be different for each of these mechanisms, and so might be the offence's harm expectancy. But still, the principles of reallocation would be similar. Therefore, it should be possible to deduce from principles governing the use of self-defensive force to principles of police entrapment.

We should therefore begin by examining the principles governing the use of self-defensive force. When it comes to offences directed against victims, the amount of permissible force in self-defence reflects the abovementioned heavy burdens $\mathrm{D}$ creates for $\mathrm{V}$ once commission has begun and the now high probability of completion. Considering the extent and weight of these burdens, the amount of permissible force is high: extreme and even lethal self-defensive force is permitted. ${ }^{61}$ But for victimless offences, extreme self-defensive force usually becomes irrelevant, as there is no victim who needs to defend herself. This is consistent with the lower burden D imposes in such offences (due to the absence of victims). Some extensions of justificatory self-defence, such as prevention of crime or even general necessity, might be relevant; but they would normally not permit the use of radical force in the context of victimless offences - no one can legitimately e.g. kill $\mathrm{D}$ who commits an offence against the public, simply because D has not created the risks that would underlie a permission to use lethal force at the time of the commission of the offence. $^{62}$ The same principles can be applied, with necessary modifications, for the regulation of police entrapment.

${ }^{61}$ For an account of the cases in which the use of lethal self-defensive force is permitted see Fiona Leverick, Killing in Self Defence (Oxford University Press, Oxford: 2006).

${ }^{62}$ The permission to use limited force in such defences reflects only the offence's harm expectancy, and not any additional burdens like the ones created in offences against victims. 


\subsection{Entrapment: Distinguishing Offences Against Victims from Victimless Offences}

In contrast with current law and much of the existing literature, ${ }^{63}$ the proposed analysis implies that, like radical self-defensive force, entrapment would usually be legitimate in the context of offences directed against individual victims. The burdens $\mathrm{D}$ creates for potential victims prior to completion of the offence go beyond the offence's harm expectancy; they are of several types, and they are high in their accumulation. Accordingly, the use of burdensome means of reallocation is legitimate. Much like radical self-defensive force, entrapment is such a burdensome means of reallocation. Entrapment increases the probability of commission and thus also D's punishment expectancy in proportion with the additional burdens D has placed on V. Indeed, the increase in D's punishment expectancy cannot legitimately be as burdensome as self-defensive force. The burdens D creates before commission has begun are still not as high as they would be after commission has begun. But still, the burdens are of the same types, and in their accumulation they are high enough to justify an increase in D's punishment expectancy through entrapment.

For this reason, we should have no special difficulty with entrapment of a potential serial killer or robber, even where the likelihood of commission is, say, only $35 \%$. While we can say that such a potential offender is actually unlikely to go ahead and commit the offence, it still seems justifiable for the police to use entrapment to neutralize whatever risk there is of him committing the offence nevertheless. Entrapment of such defendants would work in a way similar to self-defence. The same way the robber exposes himself to self-defensive force which is more radical than the robbery's harm expectancy or the correlating punishment expectancy, the to-berobber exposes himself to preventive means which are more burdensome than the offence's harm expectancy or the correlating punishment expectancy. The grounds for permitting entrapment of defendants who create risks to individual victims are similar to the grounds for permitting the use of radical self-defensive force against such defendants.

This does not mean that all the burdens that potential victims carry should be reallocated to the defendant through entrapment; only burdens carried by reasonable, if not fully rational, potential

${ }^{63}$ See Tanovich, no. 7 above, 417; Redmayne, no. 7 above, 157. 
victims should be reallocated. The uncertainty with respect to the extent of the risk the defendant poses is burdensome for perfectly rational potential victims; and it might become more burdensome the less perfectly rational potential victims are (the irrationally anxious potential victim would over-prepare for the defendant's potential offences to an exaggerated extent). As behavioural economics has demonstrated, potential victims would be irrational to a predictable extent: they would, for example, overestimate the likelihood of memorable events, and accordingly the more preoccupied with crime or victimhood they are, the more irrationally anxious will they be. ${ }^{64}$ The legal system would therefore have to identify the burden for the reasonable, if not fully rational, potential victim and to reallocate this burden (and only this burden) to the defendant through entrapment. ${ }^{65}$

Yet in the context of victimless offences, where the question of entrapment is often sharpened, entrapment would be harder to justify. Just the way the absence of special risks for victims means that the use of radical self-defensive force becomes irrelevant and the use of radical private preventive force becomes illegitimate, the absence of such risks bears on the legitimacy of entrapment. The burdens that $\mathrm{D}$ can legitimately be made to carry prior to completion of victimless offences are only as high as the offence's original harm expectancy (the harm expectancy given D's original likelihood of commission). Yet entrapment in such circumstances would amount to increasing the likelihood of commission and thus D's punishment expectancy; and the increase is imposed without $\mathrm{D}$ creating burdens which might justify it. Entrapment would thus increase the overall risk D creates and then make him carry the new increased risk. The law of

${ }^{64}$ Amos Tversky and Daniel Kahneman (1982), 'Availability: A Heuristic for Judging Frequency and Probability', in Daniel Kahneman et al. (eds), Judgment Under Un-certainty: Heuristics and Biases 163, at 164. See also Alon Harel, 'Behavioural Analysis of Criminal Law: A Survey', 2 (2014) Bergen Journal of Criminal Law and Criminal Justice 32; Richard H. McAdams and Thomas S. Ulen, 'Behavioral Criminal Law and Economics', U of Chicago Law and Economics, Olin Working Paper No. 440; U of Chicago, Public Law Working Paper No. 244; U Illinois Law and Economics Research Paper No. LE08-035 (2008). For analysis of the implications of behavioural economics for evaluation of offenders' behaviour see for example Nuno Garoupa, 'Behavioural Economics Analysis of Crime: A Critical Review', 15 (2003) European Journal of Law and Economics 5.

${ }^{65}$ Here too, entrapment bears similarity to self-defense, where an unreasonable and disproportional defensive response might have implications not only for the actor's liability but also, potentially, for the attacker's sentence (which might be significantly reduced to reflect the excessive force she has already been subjected to). 
entrapment should therefore allow taking count of the unwarranted increase in D's punishment expectancy.

\subsection{Entrapment as a Mitigating Factor}

The law of entrapment can take count of unwarranted or exaggerated increases in the likelihood of commission and in D's punishment expectancy in the sentencing stage. The proposed analysis can thus provide theoretical support for the now-marginalized English conceptualization of entrapment as a mitigating factor. Until recent years, English law was governed by the principles of R v Sang, ${ }^{66}$ where Lord Fraser famously stated that 'when Eve, taxed with having eaten the forbidden fruit, replied 'the serpent beguiled me', her excuse was, at most, a plea in mitigation.... ${ }^{67}$ This position allows place for the courts to take count of considerations of burden reallocation. In the context of offences directed against victims, there may be cases where the police increase the likelihood of commission significantly, resulting in high increase in D's punishment expectancy. Where the court considers this increase higher than the extra-burdens D had placed on V, it can 'correct' this by mitigating the sentence. In the context of victimless offences, the police increase the likelihood of commission, and hence the expectancy of punishment, in the absence of extra-burdens created by D. D is thus exposed to a higher burden than she has created. The courts can 'correct' this too by decreasing D's punishment expectancy through mitigation. The more the police increased the likelihood of commission, the lower would the sentence be, possibly to the point of no punishment at all in appropriate cases.

Such an approach resonates with Talia Fisher's proposal to impose probabilistic punishment that takes into account the likelihood that the defendant indeed committed the crime. ${ }^{68}$ Fisher seeks to challenge 'the normative desirability of the binary all-or-nothing sentencing paradigm by showing that the uniformity of punishment in the epistemic space above the reasonable doubt threshold and the absence of any punishment below this threshold are likely to impair

${ }^{66}$ [1980] AC 402.

${ }^{67}$ ibid., 446. See also Browning v. J. W. H. Watson \{Rochester) Ltd. [1953] 1 W.L.R. 1172; Birtles (1969) 53 Cr.App.R. 469.

${ }^{68}$ Talia Fisher, 'Constitutionalism and the Criminal Law: Rethinking Criminal Trial Bifurcation', (2011) 61 The University of Toronto Law Journal 811. 
ex-ante deterrence goal'. ${ }^{69}$ Like in Fisher's model, the proposed approach to entrapment takes the likelihood of commission into account in the determination of punishment. Yet unlike Fisher's model, the proposed approach is not based on considerations of deterrence (though it is not inconsistent with such considerations). Furthermore, the proposed approach does not give rise to the same constitutional objection to which Fisher's proposal gives rise, namely that it compromises the 'beyond reasonable doubt' standard. ${ }^{70}$ In the context of entrapment, the entrapment offence, for which punishment is imposed, is proved to have been committed beyond reasonable doubt. The factor taken into account is the changes in D's punishment expectancy, which partly depend on D's original likelihood of commission.

The proposed approach can further settle some possible undesired implications of existing legal distinctions. The common distinctions might turn the legitimacy of much non-targeted police practice into luck-based: if police's suggestions or offers happen to fall on the ear of a professional criminal who encounters many opportunities to commit crime, they are legitimate; if they happen to fall on the ear of a law-abiding citizen who normally keeps away from the world of crime, they are illegitimate. But if luck determines the legitimacy of police action, this action is objectionable a-priori. And so, existing distinctions might actually provide grounds for swiping objection to police entrapment, or at least to entrapment which is not accurately targeted. ${ }^{71}$ Burden reallocation takes luck out of the picture by (a) assuming that there was some risk - even if minimal - that any entrapped defendant might commit crime, and hence any entrapped defendant created certain social burdens; (b) examining the weight of these burdens to see whether proactive policing merely pushed them back to $\mathrm{D}$, or rather involved placing on $\mathrm{D}$ burdens which were heavier than the ones she had originally created.

\subsection{Objections to the Proposed Analysis of Entrapment}

One possible objection goes to the distinction between victimless offences and offences directed against victims, suggesting that it is actually justified to increase D's punishment expectancy in the con-

\footnotetext{
${ }^{69}$ Fisher, ibid., at 819.

${ }^{70}$ Fisher, no. 69 above, at 839.

71 This might be the rationale for Dworkin's proposal to prohibit untargeted entrapment. Dworking, no. 1 above.
} 
text of the first. It is often argued that in the context of victimless offences, D's punishment expectancy is lower than it should be, since such offences are hard to detect and investigate. Entrapment thus merely increases the punishment expectancy to equate it with that of defendants committing more easily detectable offences. In Andrew Ashworth's words: 'There are certain types of offences which are not usually reported by victims ... In order to detect those who commit offences of these kinds, the police may decide to operate proactively, by setting some kind of trap'. ${ }^{72}$ From the point of view of burden reallocation, the argument is that Ds who might commit victimless offences unjustifiably carry a lower burden than Ds who might commit offences against victims.

This argument gives rise to several difficulties. First, it does not take into account the fact that D1 who commits a victimless offence creates lesser burdens than D2 who commits an offence directed against victims. The lower risk of exposure of D1 merely reflects this fact, and accordingly it is not unfair or objectionable. The correlation between the created burdens and the reallocated burdens finds expression in the lesser exposure of D1 to defensive force, as we saw; and it also finds expression in his lower punishment expectancy. There are no burdened victims who would use radical self-defensive force or would testify as a way of reallocating the burden.

Alternatively, to accept the argument regarding enforcement difficulties, one must assume that enforcement difficulties are part of the burdens $\mathrm{D}$ creates and can therefore be legitimately pushed back to D. Yet while some enforcement difficulties are indeed attributable to defendants, others are not. When enforcement is risky, e.g. because D is armed, the risk is attributable to D. In such a case, the risk is not only for law enforcement agents, but also to potential victims (even if $\mathrm{D}$ only intends to drug deal). This risk will be legitimately reallocated and placed on $\mathrm{D}$ through enforcement techniques that increase the immediate risk to D (officers will use arms) or D's punishment expectancy (entrapment). But assume, for example, an unarmed drug dealer D1 whose friends reported him to the police and another unarmed drug dealer D2 whose friends kept quiet and hence enforcement has become more difficult. It would be plainly unjustified to punish D2 more than the D1; and it would be similarly unjustified to use enforcement techniques that increase the punish-

\footnotetext{
${ }^{72}$ Ashworth, no. 7 above, 293-294. See also Dworkin, 'The Serpent Beguiled Me and I Did Eat', no. 1 above, 18; J. D. Heydon, 'The Problem of Entrapment', Cambridge Law Journal 32 (1973) p. 268, 269-270.
} 
ment expectancy for D2. ${ }^{73}$ To generalize, when defendants make enforcement more risky, these risks can legitimately be reallocated back to them, but this is not usually the case with victimless offences.

Last, it can be noted that there are many categories of offences, including offences directed against victims, which are difficult to detect and investigate. To take just a couple of examples, in domestic abuse the victims would usually not complain or cooperate with the police; and murders may in some cases be hard to investigate since there too there is no victim to testify. Compared to these, drug dealers do not really pose such a great challenge for the police, and accordingly the assumption that they merit different treatment because of the alleged special difficulty in detecting and investigating does not seem to rest on sound factual grounds.

A different objection goes to the conceptualization of entrapment as a mitigating factor. The English mitigation approach has been heavily criticized. ${ }^{74}$ The first ground for criticism, suggested by Andrew Choo, has been that when the House of Lords decided to treat entrapment as a mitigating factor, it relied mainly on weak grounds for not acknowledging entrapment as a substantive defence in law ${ }^{75}$; it did not provide grounds for acknowledging entrapment as a mitigating factor. This, however, does not mean that there are no grounds for conceptualizing entrapment as a mitigating factor.

Another ground for criticism, suggested by Andrew Ashworth, has been that "entrapment creates an offence that would probably not have been committed otherwise; ${ }^{76}$ that the right of the defendant to a

${ }^{73}$ Similarly, assume that on a given year the police have a lower budget than usual, and hence enforcement difficulties are increased. If we accept the premise that enforcement difficulties are to be placed on the shoulders of defendants, this would mean that on that year extreme enforcement measures should be permitted (e.g. surveillance should be more invasive; more force can be used by police officers to prevent crime, and extreme entrapment techniques should be allowed). We can go further and ask what 'a normal budget' is, and whether we should not place on the shoulders of defendants the burden of less-than-100\% enforcement. Clearly, full enforcement is often suboptimal - it is close to optimal only in grave personal offences like rape and murder, as demonstrated by Becker's economic analysis (no. 13 above); and we already saw that in such offences the proposed analysis too leads to the conclusion that entrapment is legitimate.

${ }^{74}$ See e.g. Choo, no. 7 above, especially pp. 454-456; Ashworth, no. 7 above.

${ }^{75}$ Such as the fact that the actus reus and the mens rea were not negated by the entrapment, and that solicitation by a private citizen would not lead to a full substantive defence.

${ }^{76}$ Ashworth, no. 7 above, at 315. 
fair trial is therefore at stake, and that where this right is violated, neither excluding the evidence nor mitigating the sentence is sufficient or adequate. ${ }^{77}$ Ashworth does contend, though, that mitigating the sentence might be appropriate where the police deploy proactive methods which fall short of entrapment. ${ }^{78}$

This approach can be reconciled with the proposed approach: Ashworth acknowledges the probabilistic nature of the question whether the offence would have been committed absent police intervention, and he seems to contend that where this probability reaches a certain low threshold, punishment should be zero (and this is appropriately achieved through stay of proceedings); where this probability is higher, punishment should be higher though not as high as in non-entrapment cases (hence mitigating factor). The proposed analysis develops this reasoning by rethinking its underlying assumptions. Mainly, it is assumed that the original high probability of commission cannot in itself justify further increase of that probability through entrapment. A justification for the further increase can only be found in extra risks D poses for potential victims where the offence is directed against such victims-extra risks which are reallocated back to her through entrapment. It has been suggested that considering entrapment as a mitigating factor accords with the probabilistic nature of the matter: it allows evaluating by how much the police increased the likelihood of commission and correcting exaggerated increase through mitigation. But it is acknowledged that sometimes the increase will be so excessive (e.g. from punishment expectancy of 1 day in prison to that of 5 years), that no punishment should be imposed - as suggested by Ashworth. Thus, the practical distance from Ashworth's proposal is not great.

Furthermore, the proposed analysis suggests that theoretically, the most appropriate conceptualization of entrapment is as a mitigating factor. This does not mean that other considerations of a more practical nature should not be taken into account when designing the law. Ashworth's approach seems to take into account the general reluctance of courts to endow mitigation where appropriate. Given this reluctance, Ashworth's stay-of-proceedings approach (with mitigation in weak cases) may indeed be preferable.

\footnotetext{
77 Ashworth, no. 7 above, at 315-316.

${ }^{78}$ Ashworth, no. 7 above, at 317. Compare with Brendon Murphy and John Anderson, 'After the Serpent Beguiled Me: Entrapment and Sentencing in Australia and Canada', Queen's L.J. 39 (2013-2014) p. 621.
} 


\section{CONCLUSIONS}

This article has argued that the existing tests for identifying illegitimate entrapment rest on unsound probabilistic assumptions. It has been shown that the existing tests wrongly presume that in some identifiable cases entrapment does not raise the probability of $\mathrm{D}$ committing crime of the same type (and hence entrapment does not raise D's punishment expectancy). However, probabilistic analysis demonstrates that this is not the case. In fact, entrapment raises the probability of crime commission, and hence also D's punishment expectancy, in the vast majority of cases; and the rare cases in which this probability is not raised are not identifiable by the existing tests.

The article then proposed that increasing the probability of commission may be justified where the relevant offence is directed against victims and hence creates special risks in addition to the offence's harm expectancy; but such an increase in the probability of commission is hardly ever justified where the relevant offence is victimless and hence creates no risks apart from the offence's harm expectancy.

It has been further suggested that the appropriate way to account for the increase in the probability of crime commission and in D's punishment expectancy following entrapment is by considering entrapment as a mitigating factor: where the increase in the probability of commission and in D's punishment expectancy is exaggerated or misplaced, this increase can be balanced through mitigation of sentence.

The proposal was based on the idea of burden reallocation which presents the 'negative' side of distributive justice (as opposed to the 'positive' side of reallocation of resources). It rested on the simple premise that those who create burdens should be the ones to carry them. Yet the idea of burden reallocation calls for further investigation and development. For example, the circumstances in which creators of burdens should carry all and only the burdens they have created should be further explored. ${ }^{79}$ I shall leave the development of this idea for future work.

${ }^{79}$ Tadros, no. 49 above. 


\section{OPEN ACCESS}

This article is distributed under the terms of the Creative Commons Attribution 4.0 International License (http://creativecommons.org/ licenses/by $/ 4.0 /$ ), which permits unrestricted use, distribution, and reproduction in any medium, provided you give appropriate credit to the original author(s) and the source, provide a link to the Creative Commons license, and indicate if changes were made. 